\title{
SOME EEG OBSERVATIONS IN CHILDREN WITH INFANTILE SPASMS TREATED WITH ACTH
}

\author{
BY \\ RUTH HARRIS \\ From The Hospital for Sick Children, Great Ormond Street, London
}

(RECEIVED FOR PUBLICATION APRIL 22, 1964)

The treatment of children suffering from the type of seizure which is part of the syndrome of infantile spasms has been disappointing since 1841. At this time Dr. W. J. West first described the attacks in his own son and was treating the child with leeches, calomel purgatives, and gum lancing. Though these measures and the others used in the cases later described by Newnham (1849) may seem bizarre, no better results were obtained when the modern anticonvulsant drugs were tried.

For some years after West's original report, papers about this condition were mainly details of cases and related to the problems of terminology and classification (Newnham, 1849; Asal and Moro, 1924; Lederer, 1926; Janz and Matthes, 1955), among others. The poor prognosis was often noted but no useful therapeutic suggestions were made.

Interest in this condition increased after the descriptions by Gibbs and Gibbs and by Hess and Neuhaus in 1952 of a particular EEG pattern found in cases suffering from the characteristic spasms. Later, Hess in 1958. reported a follow-up study of his cases of infantile epilepsy and noted a relatively good prognosis concerning the seizures in contradistinction to the psychological development.

The therapeutic situation appeared to change in 1958 when Sorel and Dusaucy-Bauloye described the remarkable clinical improvement and disappearance of the gross EEG abnormality after treatment with adrenocorticotrophic hormone (ACTH). This work was subsequently confirmed by many others including Low (1958), Gastaut, Saltiel, Raybaud, Pitot, and Meynadier (1959), Dumermuth (1959), and Stamps, Gibbs, Rosenthal, and Gibbs (1959). Following these early reports, came other papers about children similarly treated in many countries. However, if the immediate effect appeared dramatic, those authors that were able to follow-up their cases for more than a few months, such as Bower and Jeavons (1961), Bernard, Coignet, Naquet, Soulayrol, Pinsard, and Abram (1963), and Matthes and Mallmann-
Mühlberger (1963), noted that many patients relapsed both clinically and from the EEG aspect. An interesting follow-up of the cases described by Low in 1958 , published by Bray in 1963, reported that only 1 out of the 6 showing a good original response to treatment was a normal child four years later, but even this child still had an abnormal EEG. Bray commented on the limited prognostic use of the EEG in this syndrome.

\section{Material and Methods}

The present investigation was carried out on 75 children who received ACTH treatment for this syndrome and in whom the infantile spasms were the main feature. All save 13 had some other disorder, or a history of perinatal disturbance. Various degrees of mental and motor retardation were present in addition to the typical seizures. The cases studied were treated with at least one course of ACTH, 40 units of the retard preparation being given daily for about one month and then gradually discontinued. A total of 390 EEG's were obtained from these 75 children over a period of four years and were re-examined in the light of the clinical outcome up to November 1963. A preliminary report on some of this material was given to the Electroencephalographic Society (Harris and Pampiglione, 1964).

\section{Results}

EEG Features Before Treatment. All the 75 children studied had EEG's taken before beginning ACTH treatment, and these showed the main features described by Gibbs and Gibbs in 1952 as 'hypsarrhythmia', in which large amplitude generalized irregular slow waves are seen mixed with sharp waves and spikes, varying from moment to moment in duration and location (Figs. 1A, 2A, and 3A). These EEG features were found between bouts of spasms with some fluctuations in appearance, often in 


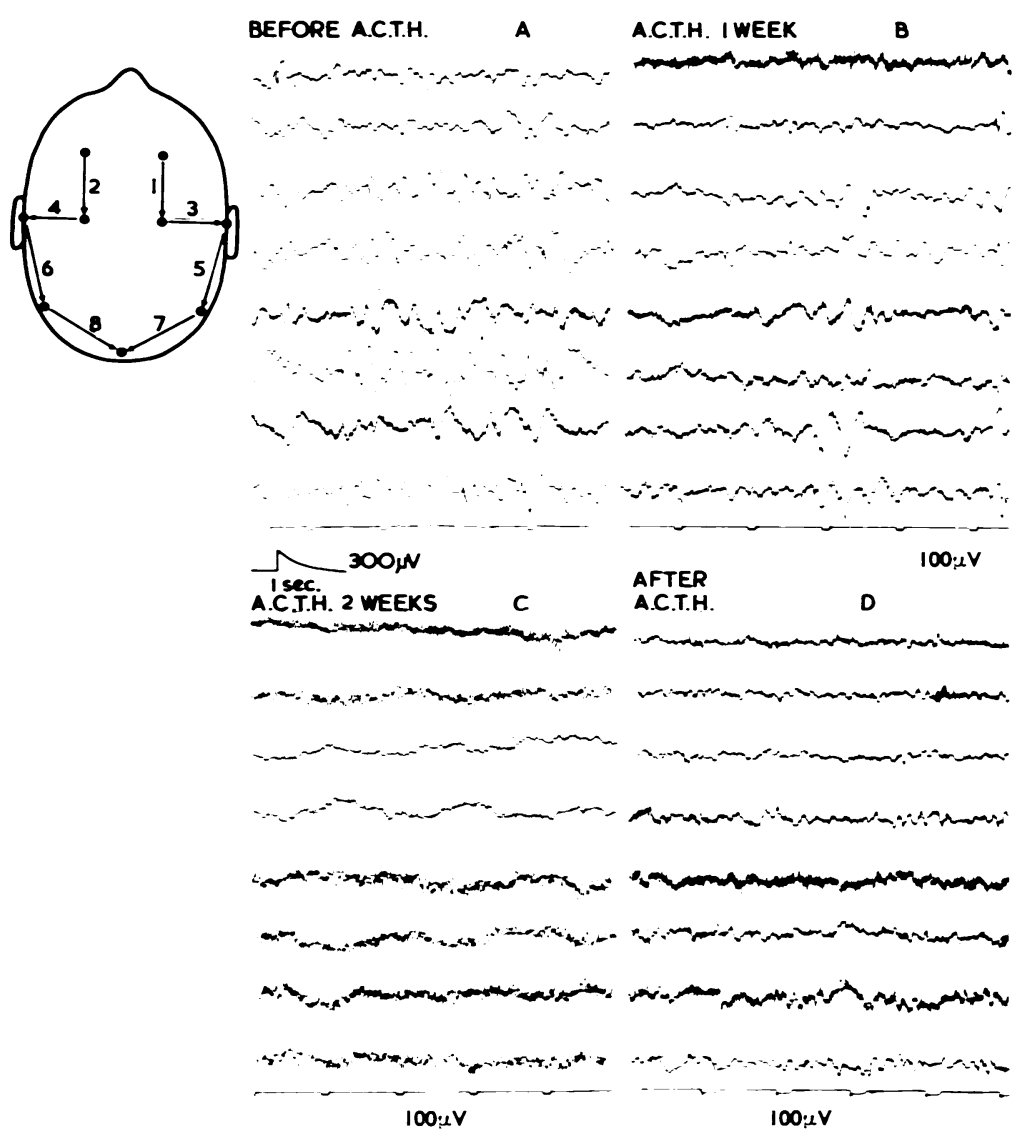

FIG. 1.-Case 1. A. Grossly abnormal EEG at 11 months before treatment: the calibration signal shown is 300 micro-volts. B. Diminution of slow activity and discharges after 1 week of ACTH. Calibration decreased to 100 micro-volts. C. Small amplitude traces partly marked by muscle action potentials after two weeks of ACTH. The baby was restless at this time. D. Fairly rhythmic activity present six weeks after the course of ACTH had ended.

relation to the sleeping or waking states. Sometimes slow waves and discharges appeared in intermittent bursts alternating every few seconds with periods of apparent equipotentiality. This variation has been described by others including Hoefer, de Napoli, and Lesse (1963). Many authors including Gastaut and Roger (1953), Druckman and Chao (1955), and Bower and Jeavons (1959) have discussed the problem of classification of the EEG. Variations in EEG patterns before therapy have been reported by various authors and occurred also in the present series probably in relation to some associated cerebral condition.

Bouts of spasms or other types of attack occurred during the test in 24 children. The EEG changes during spasms have been described previously by Gibbs and Gibbs (1952), Hess and Neuhaus (1952), Gastaut and Rémond (1952), Samson-Dollfus (1958), and Turinese (1962) among others, and similar features have been seen in the present study.

EEG Features During Treatment. As part of the treatment was often carried out in the child's own home particularly during the past two to three years, only a proportion of the patients were still in hospital while ACTH was being administered. Precisely regular intervals between EEG's were therefore not usually possible. 54 children, however, had EEGs taken during the first course of treatment, and in $\mathbf{4 2}$ children records were taken in the first ten days of therapy.

In just over half (26) of the 42 cases examined by the tenth day, there was an over-all diminution in the amplitude of the activity and discharges (see Table 2). The traces became of small amplitude after about one to two weeks of treatment. Sorel and Dusaucy- 


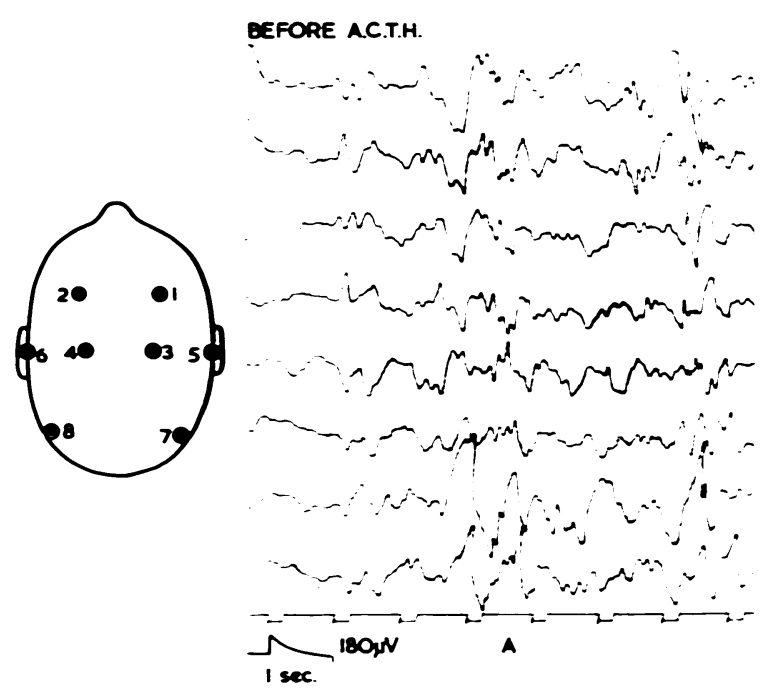

3 DAYS ON A.CT.H.

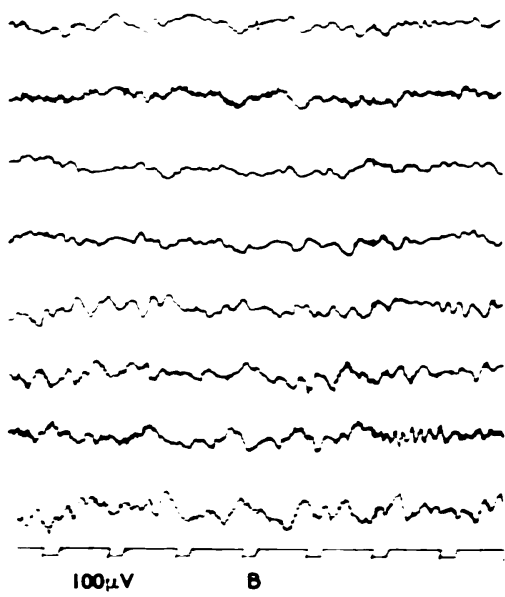

Fig. 2.- Case 2. Average reference recording using electrodes placed as in the diagram. A. Grossly abnormal EEG at 7 months of age before treatment. B. EEG after 3 days of ACTH treatment, showing a marked improvement and some fairly rhythmic activity. Calibration signal has been reduced to 100 micro-volts.

Bauloye (1958) similarly noted a rapid change in 5 out of the 7 cases they first treated with ACTH. The children were often restless after a few days of ACTH and the EEGs were often partly masked by muscle action potentials (Fig. 1C). Records during spontaneous sleep were difficult to obtain in these restless children, but when the traces had been of small amplitude and free from discharges in the waking state, discharges might reappear during spontaneous or induced sleep. Occasionally the disappearance of the gross generalized EEG abnormalities during therapy revealed evidence of localized abnormalities that could not have been previously detected with certainty (Fig. 3). and were probably related to a preexisting pathological condition.

EEG Features After First Course of Treatment. All 75 children studied had EEGs taken at the end of the first course of treatment and nearly two-thirds of these showed a marked EEG improvement (Table 1). Usually irregular intermediate slow activity of small amplitude was seen mixed with some faster and

TABLE 1

CLINICAL AND EEG STATE AT THE END OF THE FIRST COURSE OF ACTH, 75 CASES

\begin{tabular}{lll|ll|ll}
\hline Spasms & & Stopped, & $45^{*}$ & Recurred later, 15 \\
EEG & $\ldots$ &. & $\begin{array}{l}\text { Not stopped, } \\
\text { Improved, } \\
\text { Not improved, 26* }\end{array}$ & Deteriorated later, 22 \\
\hline
\end{tabular}

- 37 children were common to these two groups. slower activities. Rhythmic activity did not usually appear until some weeks after treatment was discontinued (Fig. 1D). In a few cases frequent discharges might still occur, though the general improvement was striking. The remaining third did not show any substantial EEG change at this stage though some improvement might occur during subsequent courses of ACTH.

EEG Evolution. In those cases where EEG improvement occurred, a continuous sequence of change was seen with a diminution in the amplitude of activity, disappearance of discharges, and lastly the appearance of rhythmic activity (Fig. 1). Rarely rhythmic activity appeared soon after beginning the course of ACTH (Fig. 2).

There were 49 children in whom EEG improvement had occurred by the end of the first course of ACTH (Table 1); 22 later showed a deterioration with the reappearance of irregular slow waves and discharges that were sometimes seen repeatedly over a particular region. In 17 of these, this deterioration occurred within two months of completing the course of ACTH. The other 5 showed deterioration after more than six months, but 3 of these had not had earlier EEGs taken after treatment for comparison. In some of the children showing EEG deterioration, temporary improvement occurred again in relation to a further course of ACTH.

There were 9 children whose EEGs were not substantially altered in relation to the administration 


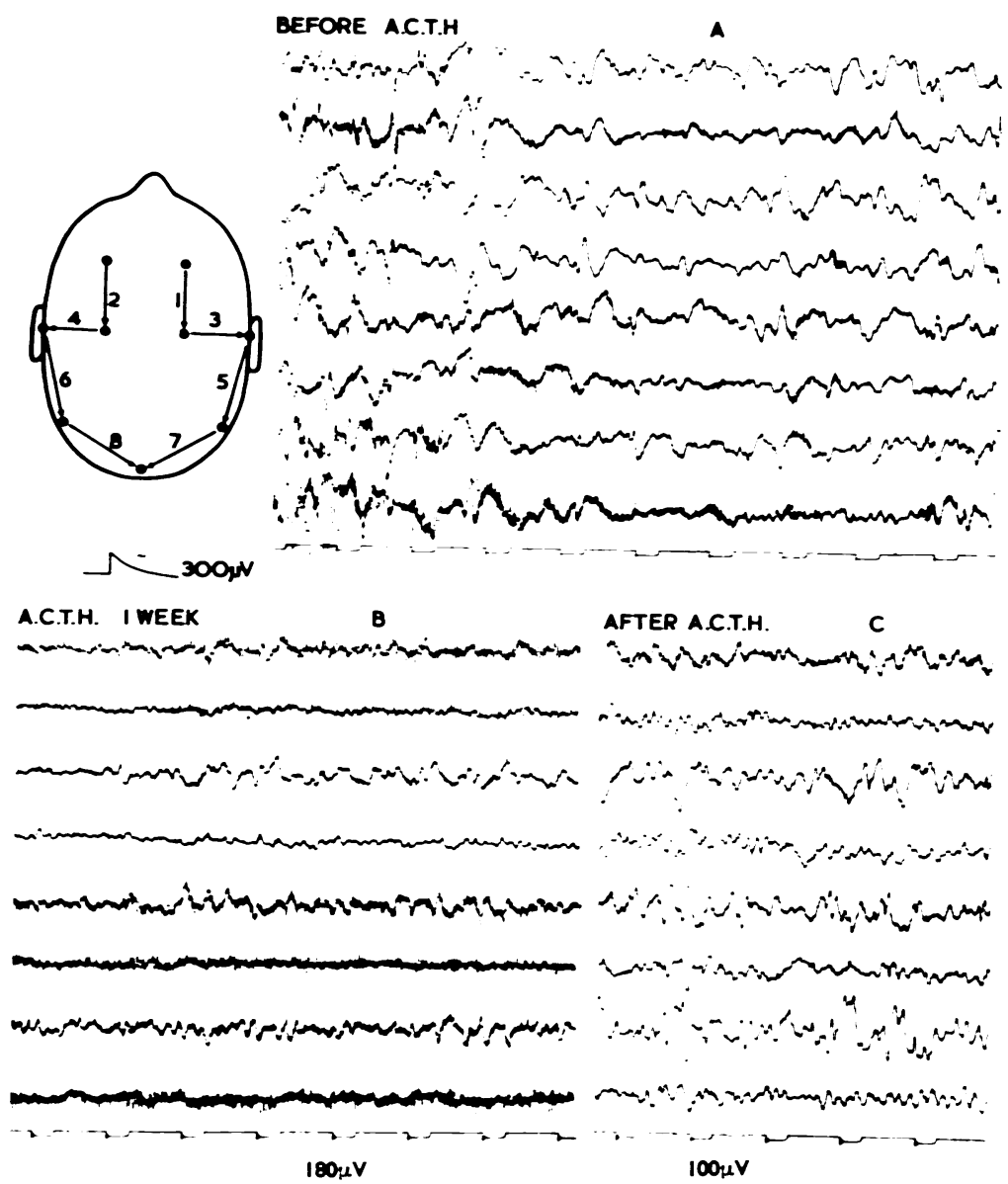

FiG. 3.-J.R. This baby had a left hemiplegia and left-sided jerking in the neonatal period and again from 4 months. Infantile spasms developed at 11 months and stopped after ACTH was given at 15 months, but the other left-sided attacks continued. A. Grossly abnormal EEG before ACTH. The asymmetry between the activities of the two hemispheres is not very marked. Calibration 300 micro-volts. B. A clear asymmetry is present after ACTH treatment for one week; the abnormality has persisted over the right hemisphere. Calibration reduced to 180 micro-volts. C. The asymmetry is still present after the course of ACTH has ended. Rhythmic activity has appeared over the left hemisphere, slow waves, spikes, and sharp waves have persisted over the right. The abnormal features in the EEG are in keeping with the lateralized clinical signs, and a marked improvement has occurred in the activity recorded over the left hemisphere.

of ACTH though treatment was given over several months. In none of these was there any beneficial clinical effect. The clinical circumstances varied and there did not appear to be any common factor present that might have been to their disadvantage. There were no common particular or unusual features in the EEGs taken before treatment from these children.

\section{Case Reports}

Case 1. (Dr. Philip Evans). This baby had been born precipitately after a full-term pregnancy and was said to have been ill and jittery in the neonatal period. Progress was subsequently normal until he began to lose interest in his surroundings at 9 months of age when infantile spasms began to occur. In addition, there were some episodes of head-turning to the right, which were difficult to evaluate. At 11 months there was mental and motor retardation, and 40 units of ACTH were given daily for one month at this age and no further spasms were seen apart from a few doubtful episodes at 14 months. The child was retarded in all ways at 2 years and 4 months of age. The EEG before treatment at 11 months showed generalized very large amplitude slow waves and multifocal discharges. An EEG taken one week after beginning ACTH treatment showed that the slow waves had become of much smaller amplitude and after two weeks of treatment there was further improvement. Very little slow activity was present at this time but the child was restless during the 
recording. Fairly rhythmic activity appeared five to six weeks later when the child was nearly 14 months old. The EEG showed no subsequent deterioration and was unremarkable at 2 years and 4 months (Fig. 1).

This case illustrates a favourable sequence of EEG change in relation to ACTH therapy and the improvement was maintained afterwards. Though spasms stopped the mental retardation remained unaltered.

Case 2. (Dr. Bernard Schlesinger) Early progress was uneventful in this child apart from the incidental finding, at another hospital, of an enlarged spleen at a routine medical examination at 7 weeks of age. This was not confirmed when he was seen at 7 months when infantile spasms began. Forty units of ACTH were given daily from 7 months of age for one month, and no further spasms occurred. He continued to gain skills but was moderately retarded at 3 years of age. The EEG taken at 7 months was grossly abnormal. Three days after ACTH treatment began there was a remarkable improvement with much less irregular activity present and some fairly rhythmic activity was seen. There was no definite EEG abnormality seen at follow-up at the age of 3 (Fig. 2).

This baby was seen and treated very soon after the onset of infantile spasms. The EEG improvement occurred very rapidly and no further spasms occurred but he was moderately retarded at follow-up.

Case 3. (Dr. Reginald Lightwood) This child progressed normally until the onset of spasms at 7 months. He was subsequently retarded in every way. 40 units of ACTH were given daily for one month when he was 10 months old. He then seemed brighter and the spasms were less severe but at 15 months he deteriorated clinically. A further course of ACTH was given of the same dosage for one month and the infantile spasms stopped briefly during this course but recurred afterwards. At 2 years and 10 months this child was very retarded with left-sided seizures in addition to infantile spasms.

An EEG taken at 10 months, before the first course of ACTH. showed generalized large amplitude irregular slow waves and multifocal discharges. Six weeks after the ACTH was first given the EEG was much improved but some irregular slow activity was still present. The EEG taken soon after the clinical deterioration at 15 months was much more abnormal, and large irregular slow waves together with multifocal spikes were seen. During the second course of ACTH the EEG features improved again, there were no discharges, and the traces became of small amplitude, though by the end of this course irregular slow waves and spikes reappeared during sleep. Subsequently the EEG abnormality increased and at 2 years and 10 months was grossly abnormal with frequent multifocal spikes and polyphasic spikes in the waking state.

The sequence of initial improvement both in the clinical and EEG aspects in relation to therapy followed by deterioration occurred in this baby during two courses of ACTH, and the final outcome was extremely poor.

Case 4. (Dr. Paul Sandifer) This baby remained well after a normal birth until 3 months of age when he had diarrhoea and vomiting and at the same time infantile spasms began. 'Drop' attacks occurred in addition to the typical spasms at 8 months and loss of skills was noted from 9 months of age. A course of prednisone was given elsewhere at 1 year and 3 months with temporary clinical improvement. ACTH was begun at 1 year and 8 months, 40 units daily being given for nearly two months and then 10 or 20 units daily for a further five months. The child was only free from spasms for a short while during the third and fourth months of treatment. Three months later when he was $2 \frac{1}{2}$ years old 40 units of ACTH daily were given again, and continued for over one month without any clinical benefit. At 2 years and 8 months, spasms and other types of seizures were still present and the child was grossly retarded. The EEG before the first course of ACTH at 1 year and 8 months showed much generalized large amplitude irregular slow activity, multifocal spikes and polyphasic spikes. Repeated records taken during the following year never showed any substantial change.

This child was seen late in the course of the illness, not until nearly a year and a half after the onset of infantile spasms. He then failed to show any response to ACTH in spite of prolonged treatment, save for a brief period of freedom from spasms, though at the time the EEG features were unaltered. The EEG was still abnormal a year after beginning therapy.

\section{Clinical and EEG Changes in Relation to First Course of ACTH}

The clinical and EEG state of the 75 children studied at the end of the first course of ACTH is summarized in Table 1.

The results seen in the 42 children with EEG studies within the first 10 days of treatment are summarized in Table 2.

\section{TABLE 2}

CLINICAL AND EEG STATE AT THE END OF 10 DAYS OF TREATMENT DURING FIRST COURSE OF ACTH, 42 CASES

\begin{tabular}{|c|c|c|c|}
\hline $\begin{array}{l}\text { Spasms } \\
\text { EEG . }\end{array}$ & $\begin{array}{l}\cdots \\
\cdots\end{array}$ & $\begin{array}{l}\text { Stopped. } \\
\text { Not stopped, } \\
\text { Improved. } \\
\text { Not improved, } 16 \\
\text { (6) }\end{array}$ & $\begin{array}{l}\text { Recurred later, } \\
\text { Deteriorated later. } 14\end{array}$ \\
\hline
\end{tabular}

* 15 children were common to these two groups.

Six children ultimately recovered and were considered to have normal mental and motor skills at follow-up. The time when spasms stopped and the EEG improved in these cases is shown in Table 3, in relation to the first course of ACTH.

These six children showed favourable EEG and clinical response within a short while of beginning therapy, five within the first two weeks of treatment (the sixth was not tested until later). There were considerable variations in the clinical circumstances of these children who did well on ACTH treatment 
TABLE 3

RESULTS SEEN IN THE SIX CHILDREN WHO RECOVERED

\begin{tabular}{lccccc}
\hline & & & & $\begin{array}{c}\text { Day of Treatment } \\
\text { When Spasms } \\
\text { Stopped }\end{array}$ & $\begin{array}{c}\text { Day of Treatment } \\
\text { When EEG } \\
\text { Improvement Soen }\end{array}$ \\
\hline S.C. & $\cdots$ & $\cdots$ & $\cdots$ & 14 & $\mathbf{8}$ \\
A.H. & $\cdots$ & $\cdots$ & $\cdots$ & 2 & $12 *$ \\
M.K. & $\cdots$ & $\cdots$ & $\cdots$ & 4 & 4 \\
P.S. & $\cdots$ & $\cdots$ & $\cdots$ & 9 & 9 \\
S.T. & $\cdots$ & $\cdots$ & $\cdots$ & 1 & $\mathbf{1 2 *}$ \\
K.T. & $\cdots$ & $\cdots$ & $\cdots$ & 1 & $30^{*}$ \\
\hline
\end{tabular}

* No eartier records obtained.

though none had begun to have spasms after the age of 9 months and all were treated from a few weeks to six months after the onset of spasms. Three of this group of children have been followed for one year after treatment, one for one and a half years and the other two for two years.

\section{Discussion}

In an illness that starts at such an early age it is often difficult to be sure that the baby has previously been normal, and subsequent clinical examination and investigations may reveal conditions that would have precluded normal development in themselves apart from the infantile spasms.

The clinical assessment of these children has not always been easy and a longer period of follow-up will be necessary before the final situation will be clear in relation to intelligence and freedom from seizures in individual cases. There are only 6 children out of the original 75 that had ACTH treatment and EEG studies, who appear to have recovered at the time of the preparation of this paper. These 6 stopped having spasms soon after beginning treatment and there was early EEG improvement. However, many other children showed an equally good response to ACTH initially and yet failed to recover. Among those who failed were 6 children without any associated conditions on examination or history of previous illness and in whom the range of age of onset and interval to treatment was similar to that of the children who responded well. In spite of this apparently equally good chance at the outset and similar treatment, these children showed variations in response to therapy and none maintained improvement if it had occurred. These findings bear out the statements of Stamps et al. (1959) and later, in 1961, of Bower and Jeavons, that it is difficult to predict before starting treatment which child might do well after an initial improvement. EEG deterioration was seen, in most cases within two months of stopping ACTH, in keeping with the findings of Mathes and Mallmann-Mühlberger in 1963.
Early treatment with ACTH was recommended by Sorel and Dusaucy-Bauloye (1958), Gastaut et al. (1959), and Low (1958, 1959), and this recommendation has been repeated in a number of subsequent publications. Millichap and Bickford (1962) found a better response among the children in his series who were treated below the age of 1 year. In this present series the majority of the children were seen and treated within six months of the onset of infantile spasms. Ten began treatment within one month of developing the illness, and none of these have recovered. Six who did recover were treated within six months of the beginning of the illness.

It is not surprising that the marked clinical and EEG response to ACTH so often seen should have led to optimism for the prognosis in children suffering from infantile spasms when this treatment was first used by Sorel and Dusaucy-Bauloye. The present study shows that there might be a better chance of recovery where the spasms stop and the EEG improves soon after treatment has begun. However, it seems that a rapid clinical and EEG response to ACTH does not always appear to be of favourable prognostic significance. None of the children without EEG improvement within one month of the first course of ACTH later did well, and in the series studied by Stamps et al. (1959) it was also noted that none became seizure free or became clinically normal where there had been no EEG improvement. Thus, in relation to the investigations available, the EEG changes show some particular trends that may help in the evaluation of ACTH therapy in children with infantile spasms.

\section{Summary}

The EEG features in 75 children suffering from infantile spasms and treated with ACTH have been described. Only six have apparently recovered at a follow-up of one to two years, though temporary favourable clinical and EEG response had been seen in many more cases. None of the patients who did not show EEG improvement in relation to the first course of ACTH eventually recovered. Some trends in the EEG changes during and after treatment may help in the evaluation of ACTH therapy.

I should like to thank all those members of the Consultant Staff of The Hospital for Sick Children who referred their cases to the Department of Clinical Neurophysiology and Electroencephalography, and also Dr. F. Elderkin, Dr. E. Tempany, and Dr. E. Wilson, the Medical Registrars, who provided the clinical details during the follow-up of most of the children. I am indebted to Dr. G. Pampiglione for his advice and encouragement in the preparation of this paper. 


\section{REFERENCES}

Asal, B., and Moro, E. (1924). Uber bösartige Nickkrämpfe im frühen Kindesalter. Jb. Kinderheilk., 107, 1.

Bernard, R., Coignet, J., Naquet, R., Soulayrol, R., Pinsard, N., and Abram, W. (1963). A propos de quelques observations du syndrome de West (spasmes en flexion avec dysrythmie majeure) à evolution prolongée. Enseignments thérapeutiques. Pédiatrie, $18,25$.

Bower, B. D., and Jeavons, P. M. (1959). Infantile spasms and hypsarrhythmia. Lancet, 1, 605.

- (1961). The effect of corticotrophin and prednisolone on infantile spasms with mental retardation. Arch. Dis. Childh., 36, 23.

Bray, P. F. (1963). The influence of adrenal steroids and corticotropin on massive myoclonic seizures of infancy. Pediatrics, 32, 169

Druckman, R., and Chao, D. (1955). Massive spasms in infancy and childhood. Epilepsia (Boston), 4, 61.

Dumermuth, G. (1959). Uber die Blitz-Nick-Salaam-Krāmpfe und ihre Behandlung mit ACTH und Hydricortison. Vorlāufige Mitteilung. Helv. paediat. Acta, 14, 250.

Gastaut, H., and Rémond, A. (1952). Etude électroencéphalographique des myoclonies. Rev. neurol., 86, 596.

- and Roger, A. (1953). Symposium sur les convulsions de l'enfance. Étude électroencéphalographique des convulsions infantiles. Pédiatrie, 8, 603.

- Saltiel, J., Raybaud, C., Pitot, M., and Meynadier, A. (1959). A propos du traitement par l'ACTH des encéphalites myocloniques de la première enfance avec dysrhythmie majeure. (Hypsarhythmia). ibid., 14, 35.

Gibbs, F. A., and Gibbs, E. L. (1952). Atlas of Electroencephalography, 2nd ed., Vol. 2, p. 25. Addison-Wesley Press, Cambridge, Massachusetts.

Harris, R., and Pampiglione, G. (1964). Some EEG observations in children with infantile spasms treated with ACTH. Electroenceph. clin. Neurophysiol., 17, 339.

Hess, R. (1958). Verlaufsuntersuchungen über Anfālle und EEG bei kindlicben Epilepsien. Arch. Psychiat. Nervenkr., 197, 568.
- and Neuhaus, T. (1952). Das Elektroencephalogramm bei Blitz-, Nick-, und Salaamkrämpfen und bei andern Anfallsformne des Kindesalters. ibid., 189, 37.

Hoefer, P. F. A., de Napoli, R. A., and Lesse, S. (1963). Periodicity and hypsarrhythmia in the EEG. A study of infantile spasms, diffuse encephalopathies, and experimental lesions of the brain. Arch. Neurol. (Chic.), 9, 424.

Janz, D., and Matthes. A. (1955). Die Propulsiv-Petit Mal-Epilepsie, Bibl. paediat. (Basel), Fasc. 60

Lederer, M. (1926). Beitrag zur Kenntnis der Nickkrämpfe. Jb. Kinderheilk., 113, 275.

Low, N. L. (1958). Infantile spasms with mental retardation. II Treatment with cortisone and adrenocorticotropin. Pediatrics, 22,1165 .

- (1959). Treatment of hypsarhythmia with ACTH and cortisone. In Molecules and Mental Health, ed. F. A. Gibbs, p. 124. Lippincott, Philadelphia and Montreal.

Matthes, A., and Mallmann-Mühlberger, E. (1963). Die PropulsivPetit-Mal-Epilepsie und ihre Behandlung mit Hormonen. Disch. med. Wschr., 88, 426.

Millichap, J. G., and Bickford, R. G. (1962). Infantile spasms, hypsarhythmia, and mental retardation. Response to corticotropin and its relation to age and etiology in 21 patients. J. Amer. med. Ass., 182, 523.

Newnham, W. (1849). History of Four Cases of Eclampsia Nutans, or the 'Salaam' convulsions of Infancy. Brit. Rec. Obstet. Med. p. 1 .

Samson-Dollfus, D. (1958). Aspect électroclinique de crises enregistrés chez des enfants présentant un tracé d'hypsarythmia. Rev. neurol., 99, 126.

Sorel, L., and Dusaucy-Bauloye, A. (1958). A propos de 21 cas d'hypsarhythmia de Gibbs. Son traitement spectaculaire par l'ACTH. Acta neurol. belg., 58, 130.

Stamps, F., Gibbs, E. L., Rosenthal, I. M., and Gibbs, F. A. (1959). Treatment of hypsarhythmia with ACTH. J. Amer. med. Ass., $171,408$.

Turinese, A. (1962). Contributo allo studio delle encefalopatie miocloniche infantili. Riv. Pat. nerv. ment., 83, 219.

West, W. J. (1841). On a peculiar form of infantile convulsions. Lancet, 1840-41, 1, 724. 